\title{
Detection of shipwrecks in ocean colour satellite imagery
}

\author{
Baeye Matthias', Rory Quinn², Samuel Deleu³ and Michael Fettweis \\ 1 OD Natural Environment, Royal Belgian Institute of Natural Sciences, Gulledelle 100, 1200 Brussels, \\ Belgium \\ E-mail: mbaeye@naturalsciences.be \\ 2 School of Environmental Sciences, Ulster University, Northern Ireland, United Kingdom \\ 3 Flemish Hydrography, Coastal Division, Agency for Maritime and Coastal Services, Flemish Ministry \\ of mobility and Public Works, Belgium
}

Waterborne swath acoustic and airborne laser systems are the main methods used to detect and investigate fully submerged shipwreck sites. In the nearshore, waterborne techniques are compromised as search tools as their effective swath is a function of water depth, necessitating very close survey line spacing in shallow water, increasing cost accordingly. Additionally, in turbid coastal waters bathymetric LiDAR is ineffective as it relies on clear non-turbid water. Therefore, the nearshore turbid zone represents a challenging area for archaeologists in the search for fully submerged archaeological sites. In this study, we describe a new methodology to detect the presence of submerged shipwrecks using ocean colour satellite imagery in turbid waters. We demonstrate that wrecks generate Suspended Particulate Matter (SPM) concentration signals that can be detected by high-resolution ocean colour satellite data such as Landsat-8. Surface SPM plumes extend downstream for up to $4 \mathrm{~km}$ from wrecks, with measured concentrations ranging between 15 and $95 \mathrm{mg} / \mathrm{l}$. The overall ratio between the plume and background SPM concentrations is about 1.4. During slack tidal phases sediments in suspension settle to create fluffy mud deposits near the seabed. Scour pits developed around wrecks act as sinks where fine-grained suspended material is preferentially deposited at slacks. The scour pits subsequently act as sources for suspended material when the bottom current increases after slacks. SPM plumes develop immediately before maximum ebb or flood current is reached, during maximum current and immediately after. Particulate matter is suspended in sufficient concentrations to be detected in ocean colour data. The ability to detect submerged shipwrecks from satellite remote sensors is of benefit to archaeological scientists and resource managers interesting in locating wrecks and investigating processes driving their evolution.

Keywords: Landsat-8; suspended sediments; shipwreck detection; bathymetry; scour pits 